Nova Southeastern University

NSUWorks

College of Psychology: Faculty Articles

College of Psychology

7-1-1986

\title{
Effect of Television Programming and Advertising on Alcohol Consumption in Normal Drinkers
}

\author{
Linda C. Sobell \\ Nova Southeastern University, sobelll@nova.edu \\ Mark B. Sobell \\ Nova Southeastern University, sobellm@nova.edu \\ Diane M. Riley \\ University of Toronto \\ Felix Klajner \\ University of Toronto \\ Gloria I.Leo \\ See next page for additional authors
}

Follow this and additional works at: https://nsuworks.nova.edu/cps_facarticles

Part of the Psychology Commons

\section{NSUWorks Citation}

Sobell, L. C., Sobell, M. B., Riley, D. M., Klajner, F., Leo, G. I., Pavan, D., Cancilla, A. (1986). Effect of Television Programming and Advertising on Alcohol Consumption in Normal Drinkers. Journal of Studies on Alcohol, 47(4), 333-340.

Available at: https://nsuworks.nova.edu/cps_facarticles/692

This Article is brought to you for free and open access by the College of Psychology at NSUWorks. It has been accepted for inclusion in College of Psychology: Faculty Articles by an authorized administrator of NSUWorks. For more information, please contact nsuworks@nova.edu. 
Authors

Linda C. Sobell, Nova Southeastern University, sobelll@nova.edu

Mark B. Sobell, Nova Southeastern University, sobellm@nova.edu

Diane M. Riley, University of Toronto

Felix Klajner, University of Toronto

Gloria I. Leo

Daniel Pavan, University of Toronto

Anthony Cancilla 


\title{
Effect of Television Programming and Advertising on Alcohol Consumption in Normal Drinkers*
}

\author{
LINDA C. SOBELL, $\uparrow$ MARK B. SOBELL, $\dagger$ DIANE M. RILEY, $\dagger$ FELIX KLAJNER, $\uparrow$ GLORIA I. LEO, \\ DANIEL PAVAN $\dagger$ AND ANTHONY CANCILLA
}

Addiction Research Foundation, Clinical Institute, 33 Russell Street, Toronto, Ontario, Canada M5S 2SI

\begin{abstract}
The drinking behavior of 96 male normal drinking college students was assessed after they viewed a videotape of a popular prime-time television program complete with advertisements. Different versions of the videotape were used to evaluate the effects of a television program with and without alcohol scenes as crossed with the effects of three different types of advertisements (i.e., beer, nonalcoholic beverages and food). After viewing the videotape, the subjects, who were led to believe that they were participating in two separate and unrelated sets of experimental procedures, were asked to perform a taste rating of light beers, which actually
\end{abstract}

provided an unobtrusive measure of their alcohol consumption. The results provided no support for the widely held assumption that drinking scenes in television programs or televised advertisements for alcoholic beverages precipitate increased drinking by viewers. This finding, however, must be considered in the context of the laboratory setting of the study, and thus may not generalize to real-life television viewing. Further research in this area is clearly needed, including an evaluation of the effects of television program content and advertisements on other populations (e.g., alcohol abusers). ( $J$. Stud. Alcohol 47: 333-340, 1986)
$\mathrm{I}^{\mathrm{T}}$ T IS COMMONLY assumed that television programming and advertising practices can have a broad impact on viewers' behavior. With respect to drinking behavior, there is a widely held belief that television programs and advertisements depicting or advocating alcohol use may precipitate increased drinking among viewers. Although it has been shown that many television programs contain extensive portrayals of alcohol use (e.g., Greenberg, 1981) and that numerous alcoholic beverage advertisements appear on network television (e.g., Atkin et al., 1983), the empirical evidence on the effects of such cues on actual alcohol consumption is surprisingly sparse and inconclusive (for review, see Cafiso et al., 1982; Comstock, 1976; Kohn and Smart, 1984).

With respect to program content, the first studies (McEwen and Hanneman, 1974; Smart and Krakowski, 1973) examining alcohol use and portrayals in television programs showed a surprisingly high frequency of such cues. This continues to be the case in more recent research (Cafiso et al., 1982; DeFoe et al., 1983; Futch et al., 1984; Greenberg, 1981). How such cues affect

Received: 13 May 1985. Revision: 1 December 1985.

* The views expressed in this article are not those of the authors and do not necessarily reflect those of the Addiction Research Foundation.

$\dagger$ Drs. L. Sobell, M. Sobell, Riley and Kaljner are also with the Department of Psychology, University of Toronto. Mr. Pavan is now with the Engineering Department, University of Toronto. viewers' actual drinking behavior, however, remains to be directly examined. At this writing, only one indirect investigation has addressed this question. In a randomized laboratory trial, Rychtarik et al. (1983) found that children (aged 8-11) who were shown the television program " $\mathrm{M}^{*} \mathrm{~A} \mathrm{~S}^{*} \mathrm{H}$ " were subsequently more likely to choose an alcoholic beverage over water as the beverage most appropriate for serving to "pictured" adults than were children who viewed the same program with the drinking scenes deleted or children who did not watch the television program. While these results suggest that television programs may influence children's attitudes toward alcohol use, the effects of television program content on actual drinking behavior were not investigated.

While the effects of alcohol cues in television programs have received little attention, the possible effects of television advertisements for alcoholic beverages have been hotly debated. On the one hand, the alcoholic beverage industry asserts that "they do not design their advertising to convince people to drink more. Rather, the companies say that they are trying to increase their individual shares in an existing market" (Eisler, 1983, p. 45). On the other hand, several countries yielding to increasing public pressure have recently banned or restricted certain alcohol advertising on television (Atkin et al., 1983). Clearly, considerable research is needed to clarify whether and how television programming and advertising might influence viewers' behavior. Such an empirical data base could provide a basis for informed 
policy decisions, but to date only a handful of studies have examined the effects of any form of advertisements on actual drinking behavior, and only one of these has focused on television advertisements.

Three studies (Brown, 1978; Kohn et al., 1984; McCarty and Ewing, 1983) investigated the effects of magazine advertisements on drinking. In the Brown study (1978), 30 men and women normal drinkers participated in two yoked sets of procedures. One condition involved viewing slides of magazine advertisements for cigarettes and the other involved viewing magazine advertisements for alcoholic beverages. Subjects participated in both advertisement conditions on separate occasions in a counterbalanced order. In each session, after viewing the advertisements, subjects participated in a 20 -min taste test in which they were asked to identify the components of mixed drinks (vodka and tonic in various proportions), the test serving as an unobtrusive measure of alcohol consumption (Marlatt et al., 1973). It was found that subjects consumed significantly more alcohol in the taste test after viewing alcoholic beverage advertisements versus cigarette advertisements. However, these results may simply reflect increased thirst rather than increased consumption of alcohol because no nonalcoholic alternative was available. Kohn and Smart (1984) suggested that subjects in Brown's study may have been motivated to perform well in the taste test following exposure to the alcohol advertisements.

To assess the influence of magazine advertisements on alcohol consumption, McCarty and Ewing (1983) used a three-factor experimental design: sex (male/ female) $\times$ predrink (alcoholic/soft) $\times$ advertisements (alcoholic product/nonalcoholic product). Subjects were told that the aim of the study was to examine the effects of alcohol on group discussion. They first viewed slides of recent magazine advertisements and individually rated them. The group then discussed each slide and agreed on a common rating. All subjects participated in two contiguous sessions differing only in whether the advertisements rated were for alcoholic beverages or for nonalcoholic products, with the order counterbalanced across subjects. Since the study was ostensibly examining the effects of drinking on group discussion, prior to the first session (alcoholic or nonalcoholic advertisements) half of the groups prepared a mixed drink (predrink) and the other groups poured soft drinks. After completing the first session, all groups prepared mixed drinks and then completed the second session. During both sessions, subjects were free to consume the drinks, but $15 \mathrm{~min}$ before the end of the second session the experimenter removed any unfinished drinks. This procedure allowed for measurement of the amount of liquid consumed. Since subjects were free to vary the alcohol concentration of their drinks, however, it could not be determined how much alcohol (as compared to mixer) subjects had actually consumed. Based on breath alcohol levels at the end of the sessions, McCarty and Ewing interpreted their results as indicating that individuals who view advertisements for alcohol after they have been drinking are more likely to continue to drink. However, inspection of their published data does not appear to support that conclusion. First, no significant main effect for type of advertisement was found. Moreover, inspection of fluid consumption means in the predrink $\times$ advertisement interaction for breath alcohol levels, on which McCarty and Ewing based their conclusion, strongly suggests that the difference in breath alcohol levels at the end of the sessions emerged because subjects who saw the nonalcoholic advertisements first drank more during that session than did subjects who saw the nonalcoholic advertisements second. Amount of consumption during the viewing of alcoholic beverage advertisements, however, was relatively constant, regardless of order of presentation. Thus the difference in final breath alcohol levels appears to have resulted from differences in drinking while viewing advertisements for nonalcoholic products.

Kohn et al. (1984) attempted a more naturalistic evaluation of the effects of exposure to magazine advertisements. Subjects were interviewed at a local shopping mall and randomly assigned to three groups: lifestyle advertisements for beer, "tombstone" advertisements (i.e., limited to depictions of the product itself and a statement about its characteristics) for beer, or a no-exposure control. Subjects first rated various aspects of the advertisements in what the authors described as an attempt to require "unusually intensive" exposure to the materials. They were then given a $\$ 5.00$ voucher that could be used on that day for the purchase of food only in a restaurant in the mall. Alcohol consumption was assessed for subjects who used the voucher. Subjects were reinterviewed 6-12 weeks later to assess the long-term effects of the study on their regular alcohol consumption. Since no significant differences were found across groups, the authors concluded that exposure to alcoholic beverage advertising does not increase consumption on either a short- or long-term basis. However, while the procedure required intensive attention to the advertisements on a single occasion, this isolated manipulation did not address the issue of repeated exposure to advertisements that would most likely occur in the natural environment.

Only one study to date has examined the effects of television advertisements for alcoholic beverages on drinking behavior (Kohn and Smart, 1984). In that study, either zero, four or nine beer advertisements were embedded among other advertisements within a 90-min videotape of a soccer game. Groups of male college students viewed the tape ostensibly to rate the 
"televiewing" appeal of soccer, and were allowed to order either soft drinks or beer while viewing the program. In each advertisement condition half of the groups of subjects had beverages available from the start of the program, whereas other groups had beverages available only after the first $\mathbf{3 0} \mathrm{min}$ (presented as due to human error). The authors interpreted their results as supporting the conclusion that, while limited exposure to televised beer advertisements initially increases drinking, "over the course of the experiment as a whole, amount of advertising exposure had no significant effect on consumption" (p. 299). It was also concluded that no effects of advertising on alcohol consumption are likely to occur when drinking is studied over a longer (i.e., more than $1 \mathrm{hr}$ ) versus a shorter time period. It is difficult to evaluate the internal validity of this study, however, because no attempt was made to assess the effectiveness of the manipulation. Thus it is not known whether the subjects found nine beer advertisements aired during a 90-min period to be credible, especially in the conditions in which beverages were not available for the first $30 \mathrm{~min}$ of the program.

In summary, although the above four studies are the first to assess the effects of advertising on alcohol consumption directly, they have various methodological shortcomings, and the results are equivocal and not immediately generalizable to naturalistic settings. Moreover, three of the four studies were restricted to magazine advertisements. In addition, no empirical study published to date has examined the effects of alcohol portrayals in television programs on drinking behavior. The present study, therefore, simultaneously examined the effects on the drinking behavior of normal drinking college students of a popular prime-time television program with and without alcohol scenes, and beer and nonalcohol advertisements embedded in the program.

\section{Method}

\section{Subjects}

The subjects were 96 male students at the University of Toronto solicited by posters placed throughout the campus. The posters indicated that male students were needed to participate in two sets of experimental procedures, one evaluating prime-time television programs and the other concerning taste judgments of light beer. The posters added that eligible subjects would receive $\$ 12.50$ for participating in each set of procedures ( $\$ 25.00$ total). To be eligible for the study, subjects had to (l) sign an informed consent; (2) be at least 19 years of age (the legal drinking age in Ontario); (3) score less than 3 on the Short Michigan Alcoholism Screening Test (SMAST) (Selzer et al., 1975); (4) have a zero blood alcohol level (BAL) at the start of the session as determined by breath test (Mobat SM-9, Luckey Laboratories, Inc., San Bernardino, Calif.); (5) have no known physical problems that would prevent them from consuming alcohol; (6) report drinking alcoholic bever- ages at least once a month, with beer accounting for at least $20 \%$ of their total alcohol intake; (7) have not previously participated in any study involving a beer-tasting task at the Addiction Research Foundation; (8) agree to refrain from eating and drinking for $2 \mathrm{hr}$ prior to their scheduled appointment; and (9) be on no medication at the time of the study.

Demographic and general drinking behavior data for subjects are presented in Table 1 . The data in Table 1 are presented for all 96 subjects combined because there were no significant differences across the six groups on any variable $(2 \times 3$ analyses of variance [ANOVA] for parametrically scaled variables and chi-square tests for nonparametrically scaled variables).

\section{Experimental design}

Subjects were randomly assigned among six conditions defined by a $3 \times 2$ between-subjects factorial design. The first factor (ad type) consisted of three types of advertisements: beer, nonalcoholic beverages and food. The second factor (scene type) was operationalized as two different versions of the same prime-time television program ("Dallas"). One version (alcohol scenes) was unedited and contained numerous scenes containing alcohol cues; the other version (no alcohol scenes) was edited to eliminate scenes portraying alcohol consumption or visual or verbal references to alcoholic beverages. After viewing the videotape, each subject was asked to perform a taste-rating task of light beers, thereby providing an unobtrusive measure of alcohol consumption (Marlatt, 1978; Nathan and Briddell, 1977; Rohsenow and Marlatt, 1981). The main dependent variable in the study was the quantity $(\mathrm{ml})$ of light beer consumed by subjects in the taste test (Marlatt et al., 1973).

\section{Television program design and preparation}

The videotape, which was slightly less than $1 \mathrm{hr}$ in length, contained four groups of advertisements spaced at approximately equal intervals throughout the videotape. Since regular

TABLE 1. Mean $( \pm \mathrm{SD})$ background variables and general drinking pattern data for 96 normal drinking college students

\begin{tabular}{|c|c|}
\hline Age (yrs) & $22.55 \pm 3.70$ \\
\hline Education (yrs) & $15.62 \pm 2.58$ \\
\hline SMAST score & $0.48 \pm 0.73$ \\
\hline Regular drinker (yrs) & $5.18 \pm 3.37$ \\
\hline Total no. drinks ${ }^{a}$ & $40.07 \pm 28.15$ \\
\hline No. of drinking days ${ }^{a}$ & $11.80 \pm 6.02$ \\
\hline No. of drinks/drinking day ${ }^{a}$ & $3.32 \pm 1.75$ \\
\hline No. days $\geq 4$ drinks $^{a}$ & $4.11 \pm 3.85$ \\
\hline Ethnicity: White $(\%)$ & 84.38 \\
\hline Beer consumption $(\%)$ & 72.00 \\
\hline \multicolumn{2}{|l|}{ Cahalan QF score $(\%)$} \\
\hline Heavy drinker & 56.25 \\
\hline Moderate drinker & 21.88 \\
\hline Light drinker & 21.88 \\
\hline
\end{tabular}


network programs typically have multiple advertisements at the commercial breaks, each group of advertisements contained three commercials. The first advertisement in each group of three always represented the ad-type condition-beer, nonalcoholic beverages or food. The remaining advertisements (8 total, 2 in each advertisement group) were "filler" advertisements (e.g., for clothes, cars, detergent) and were identical for all ad-type conditions. All advertisements had appeared on commercial television. There were three different regularstrength (i.e., not "light") beer advertisements. (One advertisement was repeated as part of the first and fourth group of advertisements.) The nonalcoholic beverage advertisement condition (i.e., coffee, a fruit drink, tea and a soft drink) was intended to control for the effects of advertisements that might precipitate fluid consumption in general. The food advertisement condition (i.e., potato chips, hot dogs, pasta and soda crackers) served as a control for any appetitive effects of advertisements.

The television program, "Dallas," was selected for use in the present study for several reasons: $(l)$ it was a current popular prime-time television drama series; (2) it had been included in previous research studies evaluating drinking portrayals in prime-time television programs (DeFoe et al., 1983; Greenberg, 1981); (3) it was evaluated as having the second highest number of drinking scenes among the top-rated television programs surveyed by Greenberg (1981) in 1979-1980 (13.3 incidents $/ \mathrm{hr}$ of programming versus an average of 8.13 incidents for all 10 programs rated, an incidence exceeded only by a program that took place in a bar setting); and (4) it used a format that contained multiple scenes, subplots and character changes that allowed for minimal disruption when editing out drinking-related scenes.

The preparation and editing of the television program, complete with advertisements, was performed by the Audio/ Visual Productions Department of the Addiction Research Foundation, which was experienced in preparing television programs for public broadcast. To select the specific "Dallas" program to be used in the present study, six consecutive weekly episodes of "Dallas" broadcast in the early months of 1983 were examined. The episode selected contained the largest number of references to drinking distributed across the greatest number of characters. The following were edited out for the no-alcohol-scenes-condition videotapes: (I) visual alcohol indicants (e.g., bottles of alcohol, home bar, signs); (2) verbal alcohol indicants (e.g., references to someone drinking, statements about drinking); (3) scenes showing actual ingestion of alcohol or the alcoholic beverage touching a character's lips; and (4) any scene that showed a character preparing to drink an alcoholic beverage (i.e., in which a character accepted, ordered, held or poured a drink but did not ingest it). Thus the no-alcohol-scenes version of the program contained no protrayals of drinking, preparing to drink or other obvious alcohol cues. The program did contain a small number of scenes that took place in a home or apartment with a home bar in the distant background. These scenes were retained because the bar was hardly apparent and their inclusion aided continuity within the episode. To equate the alcohol-scenes and no-alcohol-scenes conditions for total time, the first $14 \mathrm{~min}$ (approximately) of the next sequential "Dallas" episode (with alcohol cues edited out) were spliced onto the end of the original episode. Because "Dallas" is a series of short vignettes, the editing did not disrupt the continuity of the program and no subjects detected the deletions.

To evaluate various aspects of drinking references in the alcohol-scenes version of the program, three raters with approximately equal amounts of exposure to the program rated the program using the coding categories and scene definitions developed by DeFoe et al. (1983). In terms of ingesting alcoholic beverages, all three raters identified seven such incidents. Six characters (4 men)' accounted for these incidents, with one character drinking on two different occasions. Seven total incidents of preparing to drink alcohol were identified ( 5 characters, 3 men); six of these incidents were identified by all three raters, and one was identified by two of the raters. The 14 incidents involving both drinking and preparing to drink alcohol were also rated with respect to the reason(s) underlying the characters' drinking. The three raters agreed in their judgments for 11 of the 14 incidents; for 10 of these 11 incidents, raters judged the drinking to be for social reasons, with the remaining incident judged as crisis or escape drinking. These results are consistent with the literature showing that the predominance of alcohol portrayals on television occur in a social context (e.g., Futch et al., 1984; Greenberg, 1981; McEwen and Hanneman, 1974). The raters also evaluated verbal and visual references to alcohol in the program. Two verbal references were identified by all three raters. Fifteen visual references were identified by at least one rater; of these, 11 were noted by all three raters, and two by two of the three raters.

\section{Procedures}

Subjects participated individually in a single, two-part, 4$\mathrm{hr}$ session on weekdays during the late morning or early afternoon. Sessions were conducted by five experimenters (three women). It was planned to have experimenters run different but equal numbers of subjects in each of the six groups. This was followed except for a procedural error, which resulted in one experimenter running five rather than six total subjects in one condition and another experimenter running five rather than four total subjects in that condition. However, this did not affect the overall design since 16 subjects were run in each condition. The experimental setting for the study was a small room at the Addiction Research Foundation designed to look like a television or family room (e.g., couch, chairs, pictures, tables, a television set and low lighting).

Initial instructions. To make the two experimental procedures appear unrelated, two separate consents were used. Subjects were asked to read the first consent, which indicated that the exact nature and reasons for each of the experimental procedures would be explained at the end of the session, but that they would be informed in advance about the details of each procedure. The first consent form also stated that the first set of experimental procedures involved evaluating a

\footnotetext{
' This male : female ratio of $4: 2$ and the one noted below of $3: 2$ are similar to that reported elsewhere (Futch et al., 1984; Greenberg et al., 1979).
} 
prime-time television program. After being given a breath test to ensure they were alcohol-free, subjects completed several questionnaires designed to obtain background and general drinking pattern data: (I) SMAST (Selzer et al., 1975); (2) the Quantity-Frequency Index (Cahalan et al., 1969); and (3) the Time-line Follow-back (Sobell et al., 1979, 1986). As noted later, these questionnaries were administered to the second half of the subjects $(N=48)$ only after the completion of the second set of experimental procedures (i.e., taste test) because several subjects who received the questionnaires immediately before the first set of procedures (i.e., television viewing) became suspicious of the actual purpose of the subsequent taste test.

To enhance the credibility of the first set of procedures, subjects were first asked to peruse the television program evaluation questionnaire (6 pages with 30 items to be rated using 5-point scales) in order to become familiar with the rating system. They were further informed that their longterm rather than immediate reactions to the program were of prime interest, and they would therefore be asked to take the questionnaire home, complete it the following morning and return it by mail. To enhance the credibility of this request, subjects were given a stamped, preaddressed envelope. Subjects then viewed the television program, and immediately afterward were reminded to complete the questionnaire the next day and mail it in. As a further step to make the two sets of experimental procedures appear unrelated, after viewing the videotape subjects were told that they could then be paid $\$ 12.50$ for their participation in the first set of procedures, or that they could receive one payment of $\$ 25.00$ after the second set of procedures. All but one subject chose to be paid at the end of the second set of procedures.

Instructions for the second set of experimental procedures. After completing the first set of procedures, subjects read the second consent. The consent explained that subjects would be asked to rate the taste qualities of various light beers provided by the experimenter. This sort of taste-rating task had been used in previous studies with regular beer but not with light beer. Subjects were then given a beverage rating form with instructions for rating several taste dimensions of three different types of light beer using a series of adjectives (e.g., flat, bitter, fizzy). The three beer samples were, in fact, Carling Trilight $(2.5 \%$ ethanol). No beer advertisements in the videotape involved this brand. The adjectives appeared one at a time in the window of a memory drum manually rotated by the subjects, allowing them to work at their own pace. This also precluded a determination of how many adjectives were on the list. Subjects were instructed that when each numbered adjective appeared, they should record their ratings of each beer sample on the answer sheet with respect to that attribute using a 5-point scale $(1=$ very uncharacteristic to $5=$ very characteristic). The instructions also included an example of an adjective rating. Subjects were informed that they could drink as little or as much of each beer as they needed in order to judge it adequately, and that they did not have to sample equal amounts of each beer during the task. Finally, they were asked to rate all three samples of light beer on the same adjective before proceeding to the next adjective.
After explaining the taste-rating instructions, the experimenter brought into the room three mugs of light beer labeled $A, B$ and $C$, and reviewed the instructions with the subject. The subject then began the task, and the experimenter left the room explaining that he or she had to get something but would be back. After $20 \mathrm{~min}$, the experimenter reentered the room and asked the subject to stop since a sufficient number of adjectives had been rated.

Post-experimental procedures. At the end of the taste-rating task, the experimenter removed the tray of beer mugs and asked the subjects to complete a post-experimental questionnaire inquiring about their perceptions of the overall purpose of the study and the point at which they decided, if at all, the purpose of the study (e.g., when signing the consents, while completing the taste test). The experimenter then gave each subject a debriefing form explaining the exact nature of the study. Subjects were further informed that they could retroactively withdraw their participation now that they knew the exact nature of the study. (No subject withdrew as a result of the debriefing.) The experimenter then asked the subject not to discuss the experiment with other potential participants and administered sequential breath tests until a zero BAL was reached, at which time the subject was dismissed.

\section{Dependent measures}

Amount of beer consumed. The total amount (ml) of beer consumed in the taste test was determined by subtracting the amount of beer remaining in the three mugs from the original volume of $1023 \mathrm{ml}(341 \mathrm{ml} /$ bottle). To increase accuracy, the remaining beer was poured into a graduated cylinder prior to measurement and allowed to sit for several hours until all foam reverted to liquid.

Number of adjective ratings. Only those adjectives for which the subject had completed a rating on all three beer samples were counted as fully rated.

Amount of drinking per drinking day. Since a subject's usual drinking behavior might affect the amount consumed in a taste-rating task (Samson and Fromme, 1984), a measure of recent drinking behavior was used as a covariate in the analysis of alcohol consumption data. The covariate was the subject's reported average daily ethanol consumption per drinking day in the 30 days prior to date of the subject's last drink. These data points were derived from subjects' time-line follow-back data collected as part of the battery of questionnaires gathering general drinking pattern data. This method has been found to have good test-retest reliability with male and female normal drinking college students (Sobell et al., in press).

\section{Results}

\section{Manipulation checks}

To obtain usable data on 96 subjects, a total of 117 subjects completed the experimental procedures. Six subjects were excluded because they failed to perform the adjective-rating task as instructed; one was excluded 
TABLE 2. Observed (ANOVA) and adjusted (ANCOVA) mean ( \pm SD) milliliters of beer consumed by subjects in six experimental conditions and across conditions

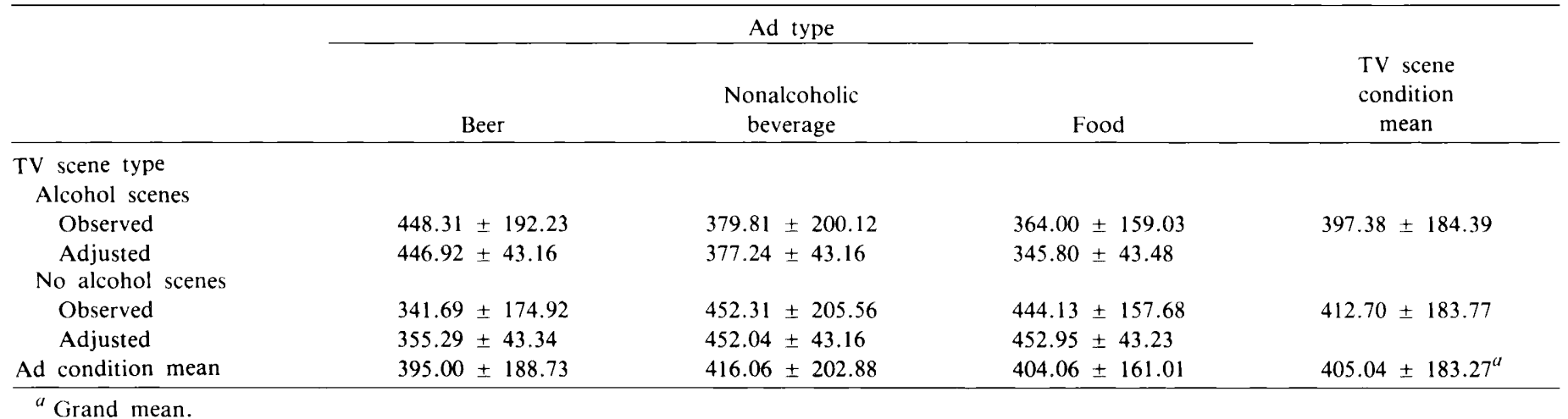

because he indicated at the debriefing that a friend had told him about the study prior to his own participation. An additional 14 subjects were excluded: 6 because they correctly indicated on the post-experimental questionnaire the general nature of the study (i.e., that the two experimental procedures were related) and 8 because they indicated that the taste-rating task was intended to measure their beer consumption. Several of these 14 subjects indicated that they became suspicious because drinking history questionnaires were administered at the beginning of the study. This became apparent early in the study. Therefore, after 48 subjects (one-half) had been run, the second 48 were administered the drinking history questionnaires after the second set of experimental procedures. This procedural change was effective; only 4 subjects were excluded in the second half of the experiment whereas 10 were excluded in the first half. The 14 subjects who either guessed the true purpose of the taste-rating task or that the two sets of procedures were related were compared with the 96 subjects who did not guess on the various background and general drinking pattern variables listed in Table 1. No statistically significant differences were found for any of these variables. (Note that $t$-tests for differences between independent means were used for parametrically scaled variables and chi-square tests were used for nonparametrically scaled variables.)

Prior to the debriefing, no subject in the no-alcoholscenes conditions mentioned to any of the experimenters that the program appeared to have been edited or that scenes were missing. This indicates that the deletion of references to drinking and alcohol scenes was successful.

A $2 \times 3$ ANOVA of variance of the number of adjectives rated in the taste-rating task revealed no significant differences among the six groups of subjects. The mean ( \pm SD) number of adjectives rated across all 96 subjects was $39.81 \pm 17.24$. Thus the subjects in the different groups did not appear to attend to the tasterating task differentially.

\section{Alcohol consumption}

The total amount $(\mathrm{ml})$ of beer consumed by subjects in the taste test constituted the main dependent variable. Table 2 presents the observed and adjusted means and standard deviations for this variable for subjects in the various conditions. A 2 (scene type) $\times 3$ (ad type) analysis of covariance (ANCOVA), with the covariate being the mean amount of alcohol consumed per drinking day by subjects over the 30 days prior to the date of their last drink, revealed no significant main effects. The interaction, however, closely approached significance $(p=.052){ }^{2}$ A similar ANOVA (i.e., $\left.2 \times 3\right)$ not involving the covariate also resulted in no significant main effects.

In a further analysis, data for subjects in the two advertisement control conditions were pooled and a 2 (scene type) $\times 2$ (ad type) ANCOVA was performed. The advertisement control conditions were combined because the conditions differed from each other in very minor ways (thirst versus general appetitive control), and pooling the control groups would provide a more powerful test of the interaction of central interest. As in the previous analysis, no significant main effects were found. The interaction, however, was statistically significant $(F=6.08,1 / 91 \mathrm{df}, p=.016)$. A simple effects analysis for scene type within ad type revealed that the scene-type conditions differed significantly only within the control advertisement level $(p=.037) .^{3}$

\footnotetext{
2 With respect to this interaction, the data were reviewed for outliers and other statistical artifacts and none were found.

3 The finding of a significant difference at the level of control advertisements most likely resulted from the increased sample size at this level based on the pooled control groups. The magnitude of the difference $(76.31 \mathrm{ml})$ was so small, however, that although it was statistically significant, it probably has little practical importance.
} 


\section{Discussion}

The major finding of the present study is that, under the conditions tested in this experiment, neither drinking scenes in television programs nor beer commercials on television precipitated increased drinking by viewers. Male college students who were exposed to a videotaped television program with alcohol scenes and beer commercials consumed approximately the same amount of beer in a subsequent taste test (mean $=448.31 \mathrm{ml}$ ) as did subjects who were exposed to videotapes featuring neither alcohol scenes nor beer advertisements (pooled mean $=448.22 \mathrm{ml}$ ). This finding, however, must be tempered by a number of caveats. First, the subjects were normal drinking men college students, and it is not known whether the present finding can be generalized to other populations. Second, subjects viewed the program in isolation, rather than in a social context, and in a setting which, although constructed to appear like a home environment, may nevertheless have been perceived as a laboratory setting, especially since the study was conducted at the Addiction Research Foundation. Third, the study was conducted during the day rather than during the evening, when prime-time television programs are broadcast. Fourth, we tested drinking immediately subsequent to viewing a single program. In this regard, it is possible that delayed effects may occur following repeated exposures to such programming. In fact, it has been suggested that the effects of mass media might be dependent on the frequency of exposure (e.g., Atkin et al., 1983; Liebert and Schwartzberg, 1977).

The above caveats simply underscore the fact that a single study cannot address the numerous factors that may influence the effects that television has on its viewers. However, to the extent that one set of parameters was tested in the present study, the central finding-that drinking cues in programs and beer advertisements did not increase drinking among viewers-is consistent with the overall conclusion of Kohn and Smart (1984) in the only other experimental study on this topic reported to date.

The interaction between scene type and ad type found in this study is perplexing and not readily explainable. However, since the overall group differences in beer consumption obtained among the various conditions were small in terms of actual magnitude (the largest difference was less than 4 fluid oz), it is not clear that the interaction can be ascribed any importance.

Finally, similar research using alcohol abusers as subjects is necessary because several studies lend empirical support to the hypothesis that alcohol abusers in contrast to nonproblem drinkers, are more responsive to environmental alcohol-related stimuli than to internal alcohol-related stimuli (Brown and Williams, 1975; Buck,
1979; Tucker et al., 1979; Williams, 1977). Other research, based on conditioning theory (e.g., Poulos et al., 1981), also suggests that alcohol abusers may be especially vulnerable to alcohol cues such as advertising and visual portrayals of drinking. Thus it is possible that alcohol abusers, as compared to normal drinkers, are affected differently (e.g., in terms of increased consumption) by alcohol cues on television. Since increased drinking could have serious consequences for alcohol abusers, research on the effects of televisionrelated alcohol cues on alcohol abusers could have both clinical and theoretical implications. Such research can help build a foundation for public policy that is based on fact rather than opinion.

\section{Acknowledgments}

The authors greatly acknowledge the considerable time and assistance of Dave Britnell and his staff, especially Ken White, in taping, editing and preparing the videotapes for use in the study. We also appreciate the assistance of Reinhard Schuller in the computer analysis of the data.

\section{References}

Atkin, C. K., Neuendorf, K. And McDermott, S. The role of alcohol advertising in excessive and hazardous drinking. J. Drug Educ. 13: 313-325, 1983.

Brown, R. A. Educating young people about alcohol use in New Zealand: Whose side are we on? Brit. J. Alcohol Alcsm 13: 199204, 1978.

Brown R. A. and Williams, R. J. Internal and external cues relating to fluid intake in obese and alcoholic persons. J. Abnorm. Psychol. 84: 660-665, 1975.

Buck, F. M. A test of heightened external responsiveness in an alcoholic population. J. Abnorm. Psychol. 88: 361-368, 1979.

Cafiso, J., Goodstadt, M. S., Garlington, W. K. and Sheppard, M. A. Television portrayal of alcohol and other beverages. J. Stud. Alcohol 43: 1232-1243, 1982.

Cahalan, D., Cisin, I. H. and Crossley, H. M. American Drinking Practices: A National Study of Drinking Behavior and Attitudes. Rutgers Center of Alcohol Studies Monograph No. 6, New Brunswick, N.J., 1969.

Comstock, G. Television and Alcohol Consumption and Abuse. The Rand Paper Series, Report P-5621, Santa Monica, Calif.: Rand Corp., 1976.

DeFoe, J. R., Breed, W. and Breed, L. A. Drinking on television: A five-year study. J. Drug Educ. 13: 25-38, 1983.

EISLER, D. A Lifting of Liquor Ban, Maclean's (Toronto), p. 45, 3 October 1983.

Futch, E. J., Lisman, S. A. AND Geller, M. I. An analysis of alcohol portrayal on prime-time television. Int. J. Addict. 19: 403$410,1984$.

GreEnBERG, B. S. Smoking, drugging and drinking in top rated TV series. J. Drug Educ. 11: 227-234, 1981.

Greenberg, B. S., Fernandez-Collado, C., Graef, D. Korzenny, F. AND Atkin, C. K. Trends in use of alcohol and other substances on television. J. Drug Educ. 9: 243-253, 1979.

Kohn, P. M. And Smart, R. G. The impact of television advertising on alcohol consumption: An experiment. J. Stud. Alcohol 45: 295$301,1984$.

Kohn, P. M., Smart, R. G. and Ogborne, A. C. Effects of two kinds of alcohol advertising on subsequent consumption. J. Advert. 13 (No. 1): 34-40, 48, 1984. 
Liebert, R. M. ANd Schwartzberg, N. S. Effects of mass media. Annu. Rev. Psychol. 28: 141-173, 1977.

Marlatt, G. A. Behavioral assessment of social drinking and alcoholism. In: Marlatt, G. A. and Nathan, P. E. (Eds.) Behavioral Approaches to Alcoholism, NIAAA-RUCAS Alcoholism Treatment Series No. 2, New Brunswick, N.J.: Rutgers Center of Alcohol Studies, 1978, pp. 35-57.

Marlatt, G. A., Demming, B. and Reid, J. B. Loss of control drinking in alcoholics: An experimental analogue. J. Abnorm. Psychol. 81: 233-241, 1973.

MCCARTY, D. AND EwING, J. A. Alcohol consumption while viewing alcoholic beverage advertising. Int. J. Addict. 18: 1011-1018, 1983.

McEwen, W. J. and Hanneman, G. J. The depiction of drug use in television programming. J. Drug Educ. 4: 281-293, 1974.

Nathan, P. E. AND Briddell, D. W. Behavioral assessment and treatment of alcoholism. In: Kissin, B. AND Begleiter, H. (Eds.) The Biology of Alcoholism, Vol. 5, Treatment and Rehabilitation of the Chronic Alcoholic, New York: Plenum Press, 1977, pp. 301-349.

Poulos, C. X., Hinson, R. E. And Siegel, S. The role of Pavlovian processes in drug tolerance and dependence: Implications for treatment. Addict. Behav. 6: 205-212, 1981.

Rohsenow, D. J. And Marlatt, G. A. The balanced placebo design: Methodological considerations. Addict. Behav. 6: 107-122, 1981.

Rychtarik, R. G., Fairbank, J. A., Allen, C. M., Foy, D. W.
AND Drabman, R. S. Alcohol use in television programming: Effects on children's behavior. Addict. Behav. 8: 19-22, 1983.

Samson, H. H. and Fromme, K. Social drinking in a simulated tavern: An experimental analysis. Drug Alcohol Depend. 14: 141$163,1984$.

Selzer, M. L., Vinokur, A. AND Van-Rooijen, L. A self-administered Short Michigan Alcoholism Screening Test (SMAST). J. Stud. Alcohol 36: 117-126, 1975.

SMart, R. G. AND KRakowski, M. The nature and frequency of drugs content in magazines and on television. J. Alcohol Drug Educ. 18 (No. 3): 16-23, 1973.

Sobell, L. C., Maisto, S. A., Sobell, M. B. ANd Cooper, A. M. Reliability of alcohol abusers' self-reports of drinking behavior. Behav. Res. Ther. 17: 157-160, 1979.

Sobell, M. B., Sobell, L. C., Klajner, F., Pavan, D. and Basian, E. The reliability of a timeline method for assessing normal drinkers college students' recent drinking history: Utility for alcohol research. Addict. Behav. 11: 149-162, 1986.

Tucker, J. A., Vuchinich, R. E. AND Sobell, M. B. Differential discriminative stimulus control of nonalcoholic beverage consumption in alcoholics and in normal drinkers. J. Abnorm. Psychol. 88: 145-152, 1979.

Williams, R. J. Effects of deprivation and pre-loading on the experimental consumption of tea by alcoholics and social drinkers. Brit. J. Addict. 72: 31-35, 1977. 